\title{
Health Care Device to Detect Various Diseases
}

\author{
Vaishnavi Mhatre, Shravani Chaugule, Shravani Fulari, Prajakta Jadhav \\ Department of Computer Engineering, SRCOE, Pune, Maharashtra, India
}

\section{ABSTRACT}

In today's world we have many fields where we use Internet of Things (IoT). It is now applicable in the medical field. The medical devices collect the information and gives us an idea about the symptoms of the diseases the person is suffering from.

Keywords : IoT, Machine Learning, Deep Learning, NN, Cloud Computing

\section{INTRODUCTION}

In today's world we have many fields where we use IoT. It is now applicable in the medical field. The medical devices collect the information and gives us an idea about the symptoms of the diseases the person is suffering from. When internet is available ordinary medical devices can collect patient's data, give extra insight into symptoms and trends, and generally give patients more control over their lives and treatment.

\section{METHODS AND MATERIAL}

It is imperative in today's world to create an electronic wearable device in order to measure vital signs in longer period. Heart rate variability is the phenomenon used to detects rate of heartbeats. The heart rate of a person changes every moment and provides a high signal aggregating local emotional arousal and broad physiological activity.

Consider old age people lives in their home alone during day time because their son/daughter goes to work and grandchildren's goes to school. During these times no one will be there to take care or them. Even if a person falls down, a mild stroke occurs, temperature increases the first aid will only get when someone notice it, it may take long time since no one is there. This may lead to situations that we lose them.

\section{RESULTS AND DISCUSSION}

To overcome this situation, we proposed to create a wearable device or simply a Health detection band. It monitors the motions and status of the person, heart beat rate, temperature, viral infections, bio-readings and other types of air to air contamination viruses which will lead to infection vectors to make you sick. If there seems A Sudden fall due to heart attacks or loosing balance, or abnormal fall or rise in heart beat rate it alters the nearby ones of the person to get immediate attention, the device also measures the temperature of the person in order to understand the person health condition.

It includes emergency response tokens includes, SMS and Call once a critical situation occurs, Device automatically makes a call and sends SMS to store contacts as well as sends official E-mail to stored Hospital details.

Another most important part of this project is that all information which is collected by device will be processed through Machine Learning enabled 
application which will use predefined or pre created datasets of the different diseases and health problems which can be assist or detect by wearable device with the help of different sensors and modules installed and configure on the proposed device.

This device is a light weight and effective in a manner so that any person can wear it properly on wrist or can carry in pocket in such order to be as close as possible to body. Using a cloud base IoT plat form combining with hardware gives a positive possibility to detect diseases using ultra-modern Machine learning application and algorithm sated and developed over Cloud.

Cloud infrastructure enable us to create and deploy application without external or additional hardware requirement to process data collected by proposed device making device light weight and possible to keep a nature (Wearable).

\section{CONCLUSION}

After successfully completion of the device will be testing against possible detections of the various diseases and skin as well as body types. Analysing its effects will be increasing disease dataset and include more modules to detect blood tests to support accuracy and detection of further illness and major disease which can be only identified by testing blood or urine $\mathrm{PH}$ level.

\section{Advantages}

- 1st ever Arduino based device having collective measures for viral infections as well as machine learning backed processing for faster and accurate detection of the health problem.

- A smart device which can be wear on wrist or can be carry in pocket
- Device can be used by any age group and gender

- Fast processing of the collected data

- Extensible use of Cloud based IoT platform and Machine learning application

- In house developed and low-cost medical instrument

- Battery as well as rechargeable power outlet

- Inbuilt internet connectivity using LTE protocol for uninterrupted network fetched by mobile networks.

- Cloud platform interaction for processing Machine learning heavy protocols

- Light weight device

- All major diseases are covered with device

\section{SYSTEM ARCHITECTURE}

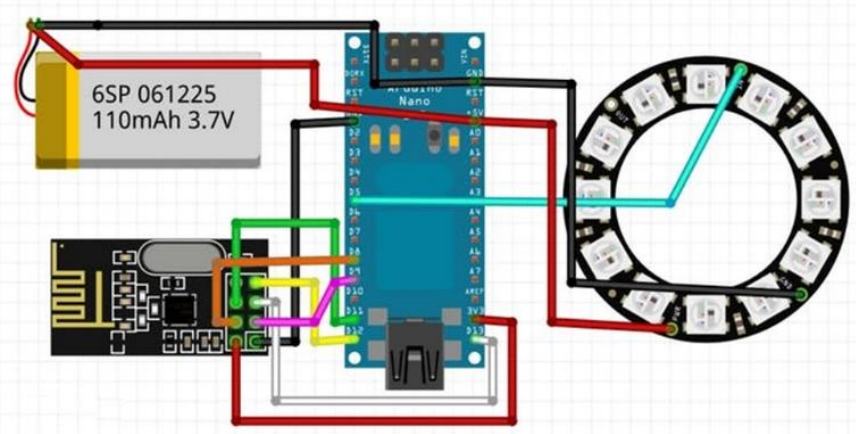

The above figure describes the proposed system architecture which gives the overall idea about the developing system device. We are trying to build a device based on IoT and Machine Learning.

All the data regarding the diseases will be stored on the cloud. The user will have to save the medical details at the beginning. The person can wear the device on wrist or can keep it in the pocket. Whenever there are signs of diseases or heart attack the respective led will glow indicating the disease and the device will automatically make a call and send message to the registered emergency contact as well as E-mail to stored Hospital details. 


\section{REFERENCES}

[1]. LeHong H, Velosa A. Hype cycle for the Internet of Things, 2014 [Internet]. Stamford (CT): Gartner Inc.; 2014 [cited at 2017 Jan 25]. Available from:

https:/www.gartner.com/doc/2804217/hypecycle-internet-things

[2]. Gao W, Emaminejad S, Nyein HY, Challa S, Chen $\mathrm{K}$, Peck A, et al. Fully integrated wearable sensor arrays for multiplexed in situ perspiration analysis. Nature 2016;529(7587):509-14.

[3]. Business Wire. Finding success in the new IoT ecosystem: market to reach $\$ 3.04$ trillion and 30 billion connected "Things" in 2020, IDC says [Internet]. San Francisco (CA): Business Wire; 2014 [cited at 2017 Jan Available from: http://www.businesswire.com" http://www.businesswire.com.

[4]. Evans D. The Internet of Things: how the next evolution of the Internet is changing everything [Internet].

[5]. San Jose (CA): Cisco Internet Business Solutions Group; 2011 [cited at 2017 Jan 25]. Available from:

http://www.cisco.com/c/dam/en_us/about/ac79/d ocs/innov/IoT_IBSG_0411FINAL.pdf

[6]. Xu S, Zhang Y, Jia L, Mathewson KE, Jang KI, Kim J, et al. Soft microfluidic assemblies of sensors, circuits, and radios for the skin. Science 2014;344(6179):70-4.

[7]. Martin T, Jovanov E, Raskovic D. Issues in wearable computing for medical monitoring applications: a case study of a wearable ECG monitoring device. Proceedings of the 4th International Symposium on Wearable Computers; 2000 Oct 16-17; Atlanta, GA. p. 43-9.

\section{Cite this article as :}

Vaishnavi Mhatre, Shravani Chaugule, Shravani Fulari, Prajakta Jadhav, "Health Care Device to Detect Various Diseases", International Journal of Scientific Research in Science and Technology (IJSRST), Online ISSN : 2395-602X, Print ISSN : 2395-6011, Volume 7 Issue 2, pp. 353-355, March-April 2020. Available at doi : https://doi.org/10.32628/IJSRST207252 Journal URL : http://ijsrst.com/IJSRST207252 